\title{
Roles of Matrix Metalloproteinases and Their Targets in Epileptogenesis and Seizures
}

\author{
Hiroyuki Mizoguchi', Kiyofumi Yamada ${ }^{2}$ \\ ${ }^{1}$ Futuristic Environmental Simulation Center, Research Institute of Environmental Medicine, Nagoya University, ${ }^{2}$ Department of Neuropsy- \\ chopharmacology and Hospital Pharmacy, Nagoya University Graduate School of Medicine, Nagoya, Japan
}

\begin{abstract}
Matrix metalloproteinases (MMPS) and tissue inhibitors of metalloproteinases (TIMPS) remodel the pericellular environment by regulating the cleavage of extracellular matrix proteins, cell surface components, neurotransmitter receptors, and growth factors, which together regulate cell adhesion, synaptogenesis, synaptic plasticity, and long-term potentiation. Increased MMP activity and dysregulation of the balance between MMPs and TIMPs have also been implicated in various pathological conditions. Recent studies have suggested that prolonged seizures are associated with high MMP levels in serum and neural tissues, and certain extracellular macromolecule targets may influence the pathogenesis of epilepsy and seizure. In this review, we discuss the roles of MMP activation in animal models of epilepsy.
\end{abstract}

KEY WORDS: Matrix metalloproteinase; Tissue inhibitor of metalloproteinase; Epilepsy; Seizure; Nerve growth factors.

\section{INTRODUCTION}

Matrix metalloproteinases (MMPs) remodel the pericellular environment, primarily by cleaving extracellular matrix (ECM) proteins. ${ }^{1)}$ This family of enzymes contains more than 20 members, all of which require $\mathrm{Zn}^{2+}$ to be active. Several MMPs, including all membrane-anchored forms, contain a furin motif (e.g., MMP-11, MMP-14, MMP-15, and MMP-16, among others); this region contributes to intracellular activation of the proteinases prior to their transport to extracellular areas. Activation of other MMPs requires extracellular proteolytic processing of secreted zymogens, which is performed by MMPs or specific proteinases. ${ }^{2,3)}$

The activities of MMPs are regulated by tissue inhibitors of metalloproteinases (TIMP-1 -4), a family of multifunctional secreted proteins that promote growth and regulate the cell cycle in various cell types. ${ }^{1,4)}$ MMPs and TIMPs show regional and cell-specific expression profiles during various stages of cerebellar development,

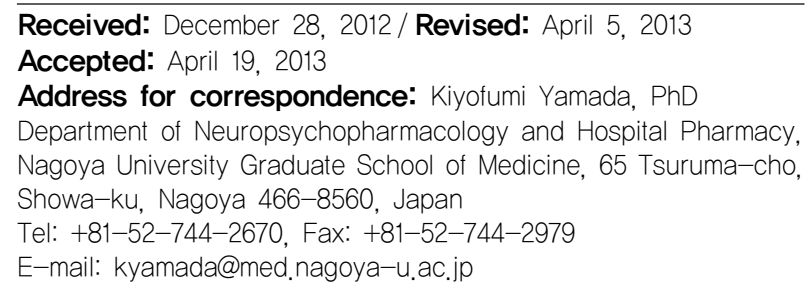

contributing to granular cell migration, arborization of Purkinje cells, and synaptogenesis. ${ }^{5)}$ The mechanisms regulating MMP expression and activity are complex. ${ }^{6)}$ In addition to posttranscriptional and epigenetic modification processes, gene transcription is regulated by a variety of growth factors, cytokines, and chemokines. ${ }^{7)}$

For example, a number of factors regulate MMP-9 expression, including prominent roles for AP1 and NF- $\mathrm{KB}$. MMP-9 is produced as an inactive proenzyme, which becomes fully activated following disruption of an interaction between a cysteine residue and a zinc ion and enzymatic removal of a propeptide. Activation of the proenzyme is controlled by a cascade that includes other MMPs and the plasmin system. Pro-MMP-9 and TIMP-1 can form a complex via their C-terminal (noninhibitory) domains, whereas low-density receptor-related protein acts as a receptor for MMP-9, mediating the internalization and degradation of the enzyme.

Levels of neuronal TIMP-1 ${ }^{8,9)}$ and MMP-9 ${ }^{10)}$ are regulated by synaptic activity, suggesting that the balance between MMPs and TIMPs contributes to activity-dependent neural reorganization and synaptic physiology. In fact, MMPs play physiological roles in neurogenesis related to memory formation and emotion. ${ }^{11,12)}$ We demonstrated that MMP-9 contributes to emotion and cognition, which may be related to activity-dependent synaptic plasticity and brain development. ${ }^{13,14)}$ MMPs and TIMPs also mod-

() This is an Open-Access article distributed under the terms of the Creative Commons Attribution Non-Commercial License (http://creativecommons.org/licenses/by-nc/3.0) which permits unrestricted non-commercial use, distribution, and reproduction in any medium, provided the original work is properly cited. 
ulate pathophysiological functional and structural remodeling in tissue, primarily by regulating cleavage of ECM proteins, bioavailability of growth factors and cytokines, and shedding of membrane receptors. ${ }^{1,3)}$ MMPs have been linked to various pathological conditions of the central nervous system, including ischemia, Alzheimer's disease, multiple sclerosis, Parkinson's disease, and malignant glioma. In particular, altered regulation of MMP-2 and MMP-9 has been linked to several nervous system disorders. ${ }^{1)}$ Not surprisingly, therefore, elucidation of the roles of MMPs in normal and abnormal brain functioning is a rapidly emerging field.

We have investigated the physiological and pathophysiological roles of MMPs and TIMPs in animal models of epilepsy. In this review, we discuss the potential contributions of MMPs - especially MMP-9 - to various physiological and pathophysiological neural processes.

\section{MAIN SUBJECTS}

\section{MMPs in Epilepsy}

Epilepsy is a chronic neurological disorder, with a prevalence of about $1-3 \%$ of people worldwide. The disorder is characterized by recurrent spontaneous seizures due to hyperactivity in the brain. ${ }^{15,16)}$ The seizures can be generated by synchronous firing of a localized group of neurons, referred to as the epileptic foci. Temporal lobe epilepsy is the most common type of epilepsy in adults and is characterized by epileptic foci in the hippocampal formation, amygdala, and temporal neocortex. ${ }^{16)}$ Seizures cause brain injuries via a number of mechanisms, and these injuries may contribute to neurological and cogni- tive deficits in patients with epilepsy. Although seizures induce neuronal death under certain conditions, nonlethal pathophysiological effects have also been noted for various brain structures and functions. ${ }^{17)}$

A variety of animal models have been developed to investigate temporal lobe epilepsy including, for example, kainate-evoked epilepsy to represent status epilepticus and pentylenetetrazole (PTZ)-induced epilepsy to reflect chemical or electrical kindling.

\section{MMP Expression in Epilepsy}

Recent studies have linked prolonged seizures with high serum MMP-9 levels and increases in the ratio of MMP-9 to TIMP-1 in patients with acute encephalopathy with dysfunction of the blood-brain barrier following prolonged febrile seizures. ${ }^{18)}$ MMP-9 protein levels were elevated in cortical lesions in patients with focal cortical dysplasia type IIb and tuberous sclerosis complex, which cause chronic epilepsy in children, suggesting a pathological role for MMP-9 in these intractable conditions. ${ }^{19)}$ Another study showed that the MMP-9 levels in cerebrospinal fluid were higher in patients with bacterial meningitis who developed secondary epilepsy than in individuals who recovered without neurological deficits, suggesting that MMP-9 concentrations contribute to postmeningitic neurological sequelae. ${ }^{20)}$ Because elevated MMP-9 levels are associated with neuronal death, aberrant synaptic plasticity, and neuroinflammation during epileptogenesis, MMP-9 is a potential therapeutic target in epilepsy. On the other hand, a recent study found no statistically significant genetic associations between single-nucleotide polymorphisms in the MMP-9 gene and

Table 1. Summary of changes in Brain MMP and TIMP levels and activities induced by chemical stimulants

\begin{tabular}{|c|c|c|c|c|c|c|c|c|}
\hline Drug & $\begin{array}{c}\text { Dose } \\
(\mathrm{mg} / \mathrm{kg})\end{array}$ & $\begin{array}{l}\text { Seizure } \\
\text { type }\end{array}$ & TIMP-1 & MMP-2 & MMP-7 & MMP-9 & $\begin{array}{c}\text { Method } \\
\text { (expression/activity) }\end{array}$ & References \\
\hline \multirow[t]{4}{*}{ Pentylenetetrazole } & 40 & Ear and facial twitching & N.D. & \pm & N.D. & \pm & Activity & 35 \\
\hline & 40 & Kindled seizure (tonic convulsion) & N.D. & \pm & N.D. & $\boldsymbol{1}$ & Protein/activity & 35 \\
\hline & 60 & Tonic convulsion & N.D. & \pm & N.D. & \pm & Activity & 35 \\
\hline & 50 & Generalized seizures & N.D. & N.D. & N.D. & $\boldsymbol{1}$ & mRNA & 22 \\
\hline \multirow[t]{5}{*}{ Kainic acid } & $1-10$ & $\begin{array}{l}\text { Tonic/clonic seizure } \\
\text { Status epilepticus }\end{array}$ & $\boldsymbol{1}$ & N.D. & N.D. & N.D. & mRNA & 8 \\
\hline & $9-10$ & Tonic convulsion & N.D. & N.D. & N.D. & $\boldsymbol{1}$ & Protein/activity & 16,31 \\
\hline & 10 & Status epilepticus & N.D. & N.D. & N.D. & $\boldsymbol{1}$ & mRNA & 23 \\
\hline & 10 & Status epilepticus & $\boldsymbol{1}$ & N.D. & $\downarrow$ & N.D. & Protein & 24 \\
\hline & 10 & Convulsion & N.D. & $\boldsymbol{1}$ & N.D. & $\boldsymbol{1}$ & Activity & 27 \\
\hline \multirow[t]{2}{*}{ Pilocarpine } & 325 & Status epilepticus & N.D. & \pm & N.D. & $\boldsymbol{1}$ & Protein/activity & 28 \\
\hline & 250 & Status epilepticus & N.D. & \pm & N.D. & $\boldsymbol{1}$ & mRNA/protein & 40 \\
\hline Bicuculline & $1.5-3.0$ & Convulsion & N.D. & $\boldsymbol{1}$ & N.D. & $\boldsymbol{1}$ & Activity & 27 \\
\hline
\end{tabular}

Modified from the review article of Mizoguchi et al. ${ }^{14)}$

\pm , no change; $\mathbf{1}$, significant increase vs. control mice; $\boldsymbol{\downarrow}$, significant decrease vs. control mice; N.D., not determined. 
temporal lobe epilepsy, although factors that influence MMP-9 expression, activation, or inhibition may play a role in the pathogenesis of temporal lobe epilepsy and other epileptic syndromes. $^{21)}$

Certain chemicals, such as pilocarpine, PTZ, and kainic acid, induce tonic convulsions and increase MMP-9 expression in rodents (Table 1). MMP-9 mRNA levels were shown to increase in response to neuronal depolarization in the rat hippocampus, ${ }^{22)}$ and MMP-9 mRNA was transported to dendrites and synapses in the hippocampal dentate gyrus of kainic acid-treated rats. ${ }^{23)}$ Twenty-four hours after kainic acid-induced seizure, MMP-7 protein and its activity decreased in the hippocampus, particularly in the CA1, whereas TIMP-1 protein levels increased in the hippocampus. ${ }^{24)}$ Expression of TIMP-1 mRNA and protein were quickly induced in the hippocampus following seizures. ${ }^{8)}$ Marked upregulation of microglial TIMP-2 expression has also been detected in dogs with seizures. ${ }^{25)}$ TIMPs are produced by microglia and astrocytes in the cortex and white matter, where the enzymes may play a role in neural regeneration depending on their expression profiles and the time after injury. ${ }^{26)}$ Although MMP-7, MMP-9, and TIMP-1 are expressed in response to neural activity in some models of epileptogenesis, ${ }^{16,24,27,28)}$ the pathophysiological and etiological roles of this metalloproteinase and its potential molecular targets are not known.

\section{MMPs in Kindled Seizure}

Kindling is an experimental epilepsy model in which repeated electrical or chemical stimulation of certain forebrain structures triggers progressively more intense electroencephalographic and behavioral seizure activities. ${ }^{29,30)}$ Once established, kindling results in a permanent state of seizure susceptibility, which may manifest as spontaneous epileptiform seizures. ${ }^{31)}$ Kindling has recently been shown to induce a variety of permanent structural changes in the brain, including sprouting of a mossy fiber pathway originating from hippocampal dentate gyrus granule cells $^{32,33)}$ and loss of neurons in the hippocampus. ${ }^{34)}$

Mice administered a single PTZ dose (20-40 mg/kg) exhibited ear and facial twitching and, at times, convulsive twitching axially throughout the body. PTZ at a dose of $60 \mathrm{mg} / \mathrm{kg}$ induced seizures characterized by tonic convulsion, jumping, and wild running. Repeated administration of PTZ at a dose of $40 \mathrm{mg} / \mathrm{kg}$ produced chemical kindling, a phenotype associated with a progressive increase in the seizure score. Repeated PTZ treatment also increases MMP-9 expression in the hippocampus for at least $24 \mathrm{~h}$ after the final dose (Table 1). On the other hand, hippocampal MMP-9 levels were not affected in mice that showed convulsive seizures in response to a single 60 $\mathrm{mg} / \mathrm{kg}$ PTZ dose. Hippocampal MMP-2 levels did not change following single or repeated PTZ doses. ${ }^{35)}$ Interestingly, electroconvulsive seizures, which can be therapeutically effective as treatment for depression, were recently shown to induce MMP-9 and TIMP-1 expression in the hippocampal vasculature of rodents. ${ }^{36)}$

We investigated the role of MMP-9 in PTZ-induced kindled seizures using MMP-9-deficient (MMP- $9^{(-/-)}$) mice. The severity of tonic seizures was similar in wild-type and MMP- $9^{(-/-)}$mice administered a single PTZ dose. Repeated administration of PTZ, however, induced kindled seizures in wild-type mice, whereas PTZ-treated MMP-9 ${ }^{(-/-)}$mice showed a marked delay in the development of kindling. These results demonstrated that deletion of MMP-9 attenuated PTZ-induced kindled seizures $^{35)}$ and supported previous findings showing that the synaptic pool of MMP-9 is a critical determinant of seizure development. ${ }^{16)}$

\section{MMP in Seizure-induced Neuronal Cell Death}

MMP-9 mRNA levels significantly increase in rodents injected with kainate, which induces status epilepticus and neuronal death in the hippocampal CA1 region and hilus. ${ }^{37)}$ Jourquin et al. ${ }^{38)}$ used organotypic cultures to demonstrate increased MMP-9 release and activity in the presence of kainate and reduced neuronal cell death following MMP-9 inhibition. Alterations in the balance between MMP-7 and TIMP-1 have been implicated in neuronal survival or death following kainic acid-induced seizures. ${ }^{24)}$ MMP-9 induced apoptotic hippocampal cell death after pilocarpine-induced status epilepticus by interrupting integrin-mediated survival signaling, suggesting that MMP-9 is a promising therapeutic target for the prevention of seizure-induced hippocampal damage. ${ }^{28)}$ A recent report showed that MMP-9 contributed to cell death after pilocarpine-induced seizures in the developing brains of infant rats. ${ }^{39)}$ An MMP inhibitor reduced cell death following pilocarpine-induced seizures, and MMP-9 knockout mice were less susceptible to seizure-induced brain injury. ${ }^{39)}$ In contrast, the $\mathrm{GABA}_{\mathrm{A}}$ receptor antagonist bicuculline induced epileptiform discharges with little or no neuronal loss. ${ }^{27,40)}$ MMP-9 levels increased 12 hours after the drug was administered, ${ }^{27)}$ suggesting that MMP-9 enzymatic activity is enhanced during the neuronal recovery period and that MMP-9 activation is associated with abnormal epileptiform activity rather than 
with processes related to cell death. ${ }^{37)}$

\section{MMP in Seizure-induced Hippocampal Neurogenesis, Synaptogenesis, and Mossy Fiber Sprouting}

Studies of neurogenesis in animal models of temporal lobe epilepsy have provided evidence for increased hippocampal neurogenesis following acute seizures. ${ }^{41,42)}$ A dramatic increase in the production of new cells and neurons was observed in the subgranular zone and granule cell layer of the dentate gyrus following pilocarpine-induced status epilepticus ${ }^{41)}$ or kindling. ${ }^{42)}$ Repeated administration of PTZ, ${ }^{43)}$ kainic acid, ${ }^{44,45)}$ or pilocarpine ${ }^{46)}$ also increased neurogenesis in the hippocampus. In fact, kainic acid-induced seizures increased the proliferation, migration, and survival of neural progenitors in the dentate gyrus, and severe seizures have been linked to aberrant migration of newborn neurons into the dentate hilus. ${ }^{45)}$ The duration of initial convulsive sustained seizures determined the patterns of hippocampal cell proliferation, neuroblast development, and subsequent evolution of spontaneous recurrent seizures in pilocarpine-treated rats. ${ }^{46)}$ Spatial and temporal profiles of MMP activities suggest that these proteinases could be an important component of neurogenesis-associated processes in the postischemic hippocampus. MMP-2 and MMP-9 have also been implicated in neuronal progenitor migration ${ }^{47)}$ and may contribute to the antidepressant effects of hippocampal neurogenesis by modulating the microenvironment in their neurogenic niche. ${ }^{48)}$ Thus, MMPs may be crucial to seizure-related neurogenesis. However, no direct evidence to support the role of MMPs or their targets in seizure-induced hippocampal neurogenesis has been produced thus far.

We demonstrated that mossy fiber sprouting induced by repeated administration of PTZ was reduced in MMP- $9^{(-1-)}$ mice compared with wild-type mice. ${ }^{35)}$ Our observations are consistent with previous findings showing that the synaptic pool of MMP-9 is critical for the mechanisms that underlie seizure development. ${ }^{16)}$ The authors generated a transgenic rat line that overexpressed MMP-9 in neurons; the mutant animals demonstrated increased susceptibility to epileptogenesis and more severe seizures. Furthermore, histological analysis showed that aberrant synaptogenesis and mossy fiber sprouting were significantly reduced in the hippocampi of MMP- $9^{(-/-)}$mice exposed to kainate. Taken together, this experimental evidence highlights a direct role for MMP-9 in synaptic remodeling induced by epileptic seizures and suggests that MMP-9 is a promising pharmacological target for the treatment of epilepsy. However, different epilepsy mo- dels ${ }^{28,37)}$ place MMP-9 in different roles, as a candidate of cell death or homeostatic synaptic plasticity, and the outcome may depend on the particular animal models of epilepsy, the amount and activity of MMP-9, and the cell types releasing MMP-9.

\section{Extracellular Macromolecule Targets of MMPs in Epileptogenesis}

\section{Neurotrophins}

Brain-derived neurotrophic factor (BDNF) is a potent morphoregulator that mediates axon branching and activity-dependent refinement of synapses. ${ }^{49,50)}$ BDNF also plays a role in epileptogenesis and kindled seizures. A recent study showed that high-frequency neuronal activity controlled the ratio of extracellular proBDNF to mature BDNF by regulating the secretion of extracellular proteases. ${ }^{51)}$ Of particular note for this review, proforms of neurotrophins are cleaved and activated by MMPs, ${ }^{2,3,52)}$ and MMP-9 converts proBDNF to mature BDNF, resulting in tropomyosin-related kinase $\mathrm{B}$ (TrkB) activation. ${ }^{2,53)}$

Repeated administration of PTZ increased BDNF mRNA and protein levels in the hippocampi of kindled wild-type mice. MMP- $9^{(-/-)}$mice showed reduced levels of mature BDNF during an early stage of kindling, which may explain the slower kindling development in the mutant animals. During later stages of kindling, however, mature BDNF levels increased to match those observed in wild-type mice. These results suggest that MMP-9 plays a role in kindling development by converting proBDNF to mature BDNF in the hippocampus, whereas other factors may be involved in mediating BDNF maturation during the later stages of kindling. This may explain why the seizure response curve of MMP- $9^{(-1-)}$ mice was markedly different from that of wild-type mice during early but not later kindling stages. ${ }^{35)}$

To examine this hypothesis, the BDNF scavenger TrkB-Fc was microinjected into the right ventricle before each dose of PTZ. TrkB-Fc significantly suppressed the development of kindling in wild-type mice, whereas no effect was observed in MMP-9 $9^{(-/-)}$mice. On the other hand, bilateral injections of proBDNF into the hippocampal dentate gyrus significantly enhanced kindling in wild-type mice but not MMP-9 ${ }^{(-1-)}$ mice. Thus, MMP-9 may be involved in the progression of behavioral phenotypes in kindled mice by converting proBDNF to mature BDNF in the hippocampus. These results likely reflect a relationship between MMP-9 expression and mature BDNF levels in the development of PTZ-induced 


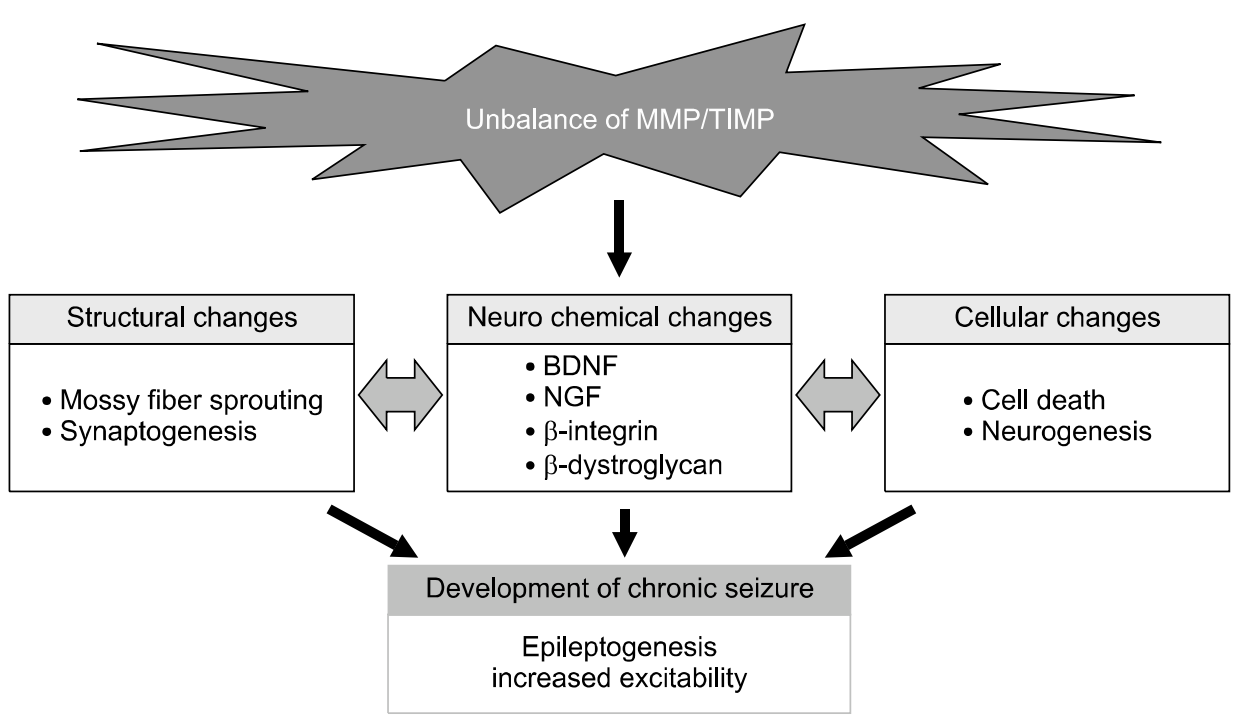

Fig. 1. Various changes induced by the unbalance of matrix metalloproteinase (MMP)/tissue inhibitors of metalloproteinase (TIMP) following seizures. Alteration of MMP/TIMP system induces the neurochemical changes in neurotrophins, proteoglycans, and integrins after status epilepticus and kindling, which is associated with structural and functional changes in the cerebral cortex and mesocorticolimbic system, leading to the development of seizure susceptibility. BDNF, brain-derived neurotrophic factor; NGF, nerve growth factor. kindling. ${ }^{35)}$ Extracellular BDNF stimulates TrkB receptors on the hilar segments of mossy fibers to induce axonal branching, which may create hyperexcitable dentate circuits. $^{54)}$ Thus, PTZ-induced kindling may develop via synaptic remodeling, including the mossy fiber sprouting induced by prolonged MMP-9 activation and subsequent increases in mature BDNF levels. These findings suggest that neural or glial MMP-9 contributes to epileptogenesis by acting on extracellular macromolecules such as BDNF (Fig. 1).

Recently, MMP-7 was demonstrated to regulate the cleavage of pro-nerve growth factor (proNGF) and provide neuroprotective effects following kainic acid-induced seizures. ${ }^{24)}$ In that study, kainic acid-induced seizures affected levels of MMP-7 and its inhibitor TIMP-1, which prevented proneurotrophin cleavage and increased proNGF levels in the extracellular milieu. In vitro and in vivo experiments have shown that exogenous MMP-7 enhances proNGF cleavage and is neuroprotective following treatment with kainic acid. Thus, the regulation of proNGF processing by MMP-7 is important for cell survival. Additionally, MMP-7 has been shown to disrupt dendritic spines in hippocampal neurons through N-methyl-D-aspartate receptor activation. ${ }^{55)}$ Thus, MMP-7 may play multiple roles related to synaptic stability in the microenvironment associated with the development of epilepsy.

\section{Other proteinases and substrates involved in epilepsy} Laminin, ${ }^{56)} \beta$-dystroglycan, ${ }^{57)}$ and neural cell adhesion molecules $(\mathrm{NCAM})^{58)}$ are also substrates of MMPs. Degradation of laminin by tissue plasminogen activator
(tPA) directly affects the dynamics of dendritic spine development, ${ }^{59)}$ and tPA and plasmin regulate seizure-induced hippocampal mossy fiber outgrowth via a proteoglycan substrate. ${ }^{60)}$ Accordingly, extracellular proteolytic factors, including MMP-9 and TPA, may play critical roles in aberrant synaptogenesis associated with epileptic seizures. tPA and plasmin mediate the processing of the NCAM ligands DSD-1-PG/phosphacan and neurocan, which is critical for appropriately terminating the extension of mossy fibers at the subgranular/molecular boundary. $^{60)}$

Michaluk et ll $^{57)}$ identified $\beta$-dystroglycan as a target for MMP-9 in response to enhanced neuronal activity. In neuronal cultures, $\beta$-dystroglycan underwent proteolysis in the presence of glutamate or bicuculline, effects that were blocked by TIMP-1. $\beta$-dystroglycan degradation has also been observed in the hippocampus in response to seizures, although not in MMP- $9^{(-/-)}$mice, and $\beta$-dystroglycan cleavage has been correlated with increased MMP-9 activity. Moreover, activity-dependent release of MMP-9 at synapses may facilitate morphological changes and synaptic reorganization. ${ }^{61)}$ Locally secreted protein may then mediate extracellular remodeling to establish persistent changes in synapse structure and function. Laminin, $\beta$-dystroglycan, and NCAM levels, however, did not change in the hippocampi of PTZ-kindled mice, even though these proteins are substrates for MMPs. ${ }^{35)}$

Integrins are also substrates for MMPs. The $\beta 1$ subtype regulates activation of the PI3K/Akt signaling pathway by interacting with integrin-linked kinase, and their loss induces apoptotic cell death by disrupting survival signaling. ${ }^{62,63)}$ Recent studies have demonstrated that activation 
of MMPs and subsequent loss or disruption of integrin signaling was induced during apoptosis. ${ }^{64,65)}$ MMP-9 plays a major role in the loss of $\beta 1$-integrin after seizure, and selective MMP-9 inhibitors can inhibit destruction of $\beta 1$-integrin. ${ }^{28)} \beta 1$-integrin is probably a direct target of MMP-9 during apoptotic hippocampal cell death after pilocarpine-induced status epilepticus. ${ }^{28)}$

\section{CONCLUSION}

Scientific and clinical research has begun to elucidate the roles of MMPs in seizures and epilepsy. Proteolytic mechanisms regulate various developmental and homeostatic processes, whereas inappropriate proteolysis causes or exacerbates a number of disorders of the central nervous system. Many studies have shown that MMPs and TIMPs are expressed in response to neural activity in models of epileptogenesis. Recent data have begun to reveal the pathophysiological and etiological roles of MMPs, as well as such potential molecular targets as neurotrophin, proteoglycan, and integrins, during the development of temporal lobe epilepsy. These results suggest that MMP overexpression is associated with structural and functional changes in the cerebral cortex and mesocorticolimbic system, leading to abnormal behaviors following seizures. In addition to contributions to various diseases, MMPs are linked to a number of physiological processes, including neurogenesis related to memory formation and emotion. More research is clearly needed to understand the diverse roles of these proteases and their potential as therapeutic targets.

\section{- Acknowledgments}

This study was supported in part by Grants-in-aid for Scientific Research (grant numbers 21790068, 22390046, 23790082, and 23659135) from the Japan Society for the Promotion of Science; a grant from the Japan Epilepsy Research Foundation; a grant from the Kowa Life Science Foundation, Japan; a grant from the Nakatomi Foundation, Japan; a grant from the Smoking Research Foundation, Japan; global COE program grants from the Ministry of Education, Culture, Sports, Science and Technology of Japan and the Academic Frontier Project for Private Universities; and a matching fund subsidy from MEXT, 2007-2011.

\section{REFERENCES}

1. Yong VW, Power C, Forsyth P, Edwards DR. Metalloproteinases in biology and pathology of the nervous system. Nat Rev Neurosci 2001;2:502-511.
2. Ethell IM, Ethell DW. Matrix metalloproteinases in brain development and remodeling: synaptic functions and targets. J Neurosci Res 2007;85:2813-2823.

3. Sternlicht MD, Werb Z. How matrix metalloproteinases regulate cell behavior. Annu Rev Cell Dev Biol 2001;17: 463-516.

4. Mannello F, Gazzanelli G. Tissue inhibitors of metalloproteinases and programmed cell death: conundrums, controversies and potential implications. Apoptosis 2001;6:479-482.

5. Vaillant C, Didier-Bazès M, Hutter A, Belin MF, Thomasset N. Spatiotemporal expression patterns of metalloproteinases and their inhibitors in the postnatal developing rat cerebellum. J Neurosci 1999;19:4994-5004.

6. Dzwonek J, Rylski M, Kaczmarek L. Matrix metalloproteinases and their endogenous inhibitors in neuronal physiology of the adult brain. FEBS Lett 2004;567:129-135.

7. Clark IM, Swingler TE, Sampieri CL, Edwards DR. The regulation of matrix metalloproteinases and their inhibitors. Int J Biochem Cell Biol 2008;40:1362-1378.

8. Rivera S, Tremblay E, Timsit S, Canals O, Ben-Ari Y, Khrestchatisky M. Tissue inhibitor of metalloproteinases-1 (TIMP-1) is differentially induced in neurons and astrocytes after seizures: evidence for developmental, immediate early gene, and lesion response. J Neurosci 1997;17:4223-4235.

9. Nedivi E, Hevroni D, Naot D, Israeli D, Citri Y. Numerous candidate plasticity-related genes revealed by differential cDNA cloning. Nature 1993;363:718-722.

10. Szklarczyk A, Lapinska J, Rylski M, McKay RD, Kaczmarek L. Matrix metalloproteinase-9 undergoes expression and activation during dendritic remodeling in adult hippocampus. J Neurosci 2002;22:920-930.

11. Nagy V, Bozdagi O, Matynia A, Balcerzyk M, Okulski P, Dzwonek J, et al. Matrix metalloproteinase-9 is required for hippocampal late-phase long-term potentiation and memory. J Neurosci 2006;26:1923-1934.

12. Meighan SE, Meighan PC, Choudhury P, Davis CJ, Olson ML, Zornes PA, et al. Effects of extracellular matrix-degrading proteases matrix metalloproteinases 3 and 9 on spatial learning and synaptic plasticity. $J$ Neurochem 2006;96: 1227-1241.

13. Mizoguchi H, Ibi D, Takuma K, Toth E, Sato J, Itohara S, et al. Alterations of emotional and cognitive behaviors in matrix metalloproteinase-2 and-9-deficient mice. Open Behav Sci $J$ 2010;4:19-25.

14. Mizoguchi H, Yamada K, Nabeshima T. Matrix metalloproteinases contribute to neuronal dysfunction in animal models of drug dependence, Alzheimer's disease, and epilepsy. Biochem Res Int 2011;681385.

15. Morimoto K, Fahnestock M, Racine RJ. Kindling and status epilepticus models of epilepsy: rewiring the brain. Prog Neurobiol 2004;73:1-60.

16. Wilczynski GM, Konopacki FA, Wilczek E, Lasiecka Z, Gorlewicz A, Michaluk P, et al. Important role of matrix metalloproteinase 9 in epileptogenesis. J Cell Biol 2008;180: 1021-1035.

17. Zeng LH, Xu L, Rensing NR, Sinatra PM, Rothman SM, Wong M. Kainate seizures cause acute dendritic injury and actin depolymerization in vivo. J Neurosci 2007;27:1160411613.

18. Suenaga N, Ichiyama T, Kubota M, Isumi H, Tohyama J, Furukawa S. Roles of matrix metalloproteinase-9 and tissue inhibitors of metalloproteinases 1 in acute encephalopathy following prolonged febrile seizures. J Neurol Sci 2008; 266:126-130. 
19. Li S, Yu S, Zhang C, Shu H, Liu S, An N, et al. Increased expression of matrix metalloproteinase 9 in cortical lesions from patients with focal cortical dysplasia type IIb and tuberous sclerosis complex. Brain Res 2012;1453:46-55.

20. Leppert D, Leib SL, Grygar C, Miller KM, Schaad UB, Holländer GA. Matrix metalloproteinase (MMP)-8 and MMP-9 in cerebrospinal fluid during bacterial meningitis: association with blood-brain barrier damage and neurological sequelae. Clin Infect Dis 2000;31:80-84.

21. Heuser K, Hoddevik EH, Taubøll E, Gjerstad L, Indahl U, Kaczmarek L, et al. Temporal lobe epilepsy and matrix metalloproteinase 9: a tempting relation but negative genetic association. Seizure 2010;19:335-338.

22. Rylski M, Amborska R, Zybura K, Michaluk P, Bielinska $\mathrm{B}$, Konopacki FA, et al. JunB is a repressor of MMP-9 transcription in depolarized rat brain neurons. Mol Cell Neurosci 2009;40:98-110.

23. Konopacki FA, Rylski M, Wilczek E, Amborska R, Detka $\mathrm{D}$, Kaczmarek L, et al. Synaptic localization of seizureinduced matrix metalloproteinase-9 $m R N A$. Neuroscience 2007;150:31-39.

24. Le AP, Friedman WJ. Matrix metalloproteinase-7 regulates cleavage of pro-nerve growth factor and is neuroprotective following kainic acid-induced seizures. J Neurosci 2012;32: 703-712.

25. Stein VM, Genini S, Puff C, Baumgärtner W, Tipold A. Seizure activity in dogs is associated with enhanced TIMP-2 expression of microglia. Vet Immunol Immunopathol 2012; 146:101-105.

26. Wright JW, Harding JW. The brain angiotensin system and extracellular matrix molecules in neural plasticity, learning, and memory. Prog Neurobiol 2004;72:263-293.

27. Zhang JW, Deb S, Gottschall PE. Regional and differential expression of gelatinases in rat brain after systemic kainic acid or bicuculline administration. Eur J Neurosci 1998; 10:3358-3368.

28. Kim GW, Kim HJ, Cho KJ, Kim HW, Cho YJ, Lee BI. The role of MMP-9 in integrin-mediated hippocampal cell death after pilocarpine-induced status epilepticus. Neurobiol Dis 2009;36:169-180.

29. Goddard GV, McIntyre DC, Leech CK. A permanent change in brain function resulting from daily electrical stimulation. Exp Neurol 1969;25:295-330.

30. Racine RJ. Modification of seizure activity by electrical stimulation. II. Motor seizure. Electroencephalogr Clin Neurophysiol 1972;32:281-294.

31. Pinel JP, Rovner LI. Electrode placement and kindlinginduced experimental epilepsy. Exp Neurol 1978;58:335346.

32. Sutula T, He XX, Cavazos J, Scott G. Synaptic reorganization in the hippocampus induced by abnormal functional activity. Science 1988;239:1147-1150.

33. Cavazos JE, Golarai G, Sutula TP. Mossy fiber synaptic reorganization induced by kindling: time course of development, progression, and permanence. J Neurosci 1991;11: 2795-2803.

34. Cavazos JE, Das I, Sutula TP. Neuronal loss induced in limbic pathways by kindling: evidence for induction of hippocampal sclerosis by repeated brief seizures. $J$ Neurosci 1994;14:3106-3121.

35. Mizoguchi H, Nakade J, Tachibana M, Ibi D, Someya E, Koike $\mathrm{H}$, et al. Matrix metalloproteinase-9 contributes to kindled seizure development in pentylenetetrazole-treated mice by converting pro-BDNF to mature BDNF in the hippocampus. J Neurosci 2011;31:12963-12971.
36. Girgenti MJ, Collier E, Sathyanesan M, Su XW, Newton SS. Characterization of electroconvulsive seizure-induced TIMP-1 and MMP-9 in hippocampal vasculature. Int J Neuropsychopharmacol 2011;14:535-544.

37. Takács E, Nyilas R, Szepesi Z, Baracskay P, Karlsen B, Røsvold $\mathrm{T}$, et al. Matrix metalloproteinase-9 activity increased by two different types of epileptic seizures that do not induce neuronal death: a possible role in homeostatic synaptic plasticity. Neurochem Int 2010;56:799-809.

38. Jourquin J, Tremblay E, Décanis N, Charton G, Hanessian $\mathrm{S}$, Chollet AM, et al. Neuronal activity-dependent increase of net matrix metalloproteinase activity is associated with MMP-9 neurotoxicity after kainate. Eur J Neurosci 2003;18: 1507-1517.

39. Hoehna Y, Uckermann O, Luksch H, Stefovska V, Marzahn $\mathrm{J}$, Theil M, et al. Matrix metalloproteinase 9 regulates cell death following pilocarpine-induced seizures in the developing brain. Neurobiol Dis 2012;48:339-347.

40. Ben-Ari Y, Tremblay E, Riche D, Ghilini G, Naquet R. Electrographic, clinical and pathological alterations following systemic administration of kainic acid, bicuculline or pentetrazole: metabolic mapping using the deoxyglucose method with special reference to the pathology of epilepsy. Neuroscience 1981;6:1361-1391.

41. Parent JM, Yu TW, Leibowitz RT, Geschwind DH, Sloviter RS, Lowenstein DH. Dentate granule cell neurogenesis is increased by seizures and contributes to aberrant network reorganization in the adult rat hippocampus. $J$ Neurosci 1997; 17:3727-3738.

42. Bengzon J, Kokaia Z, Elmér E, Nanobashvili A, Kokaia M, Lindvall O. Apoptosis and proliferation of dentate gyrus neurons after single and intermittent limbic seizures. Proc Natl Acad Sci U S A 1997;94:10432-10437.

43. Buga AM, Vintilescu R, Balseanu AT, Pop OT, Streba C, Toescu E, et al. Repeated PTZ treatment at 25-day intervals leads to a highly efficient accumulation of doublecortin in the dorsal hippocampus of rats. PLoS One 2012;7:e39302.

44. Gray WP, Sundstrom LE. Kainic acid increases the proliferation of granule cell progenitors in the dentate gyrus of the adult rat. Brain Res 1998;790:52-59.

45. Yang F, Wang JC, Han JL, Zhao G, Jiang W. Different effects of mild and severe seizures on hippocampal neurogenesis in adult rats. Hippocampus 2008;18:460-468.

46. Hung YW, Yang DI, Huang PY, Lee TS, Kuo TB, Yiu CH, et al. The duration of sustained convulsive seizures determines the pattern of hippocampal neurogenesis and the development of spontaneous epilepsy in rats. Epilepsy Res 2012;98:206-215.

47. Wang L, Zhang ZG, Zhang RL, Gregg SR, Hozeska-Solgot A, LeTourneau Y, et al. Matrix metalloproteinase 2 (MMP2) and MMP9 secreted by erythropoietin-activated endothelial cells promote neural progenitor cell migration. J Neurosci 2006;26:5996-6003.

48. Benekareddy M, Mehrotra P, Kulkarni VA, Ramakrishnan P, Dias BG, Vaidya VA. Antidepressant treatments regulate matrix metalloproteinases-2 and -9 (MMP-2/MMP-9) and tissue inhibitors of the metalloproteinases (TIMPS 1-4) in the adult rat hippocampus. Synapse 2008;62:590-600.

49. Cabelli RJ, Hohn A, Shatz CJ. Inhibition of ocular dominance column formation by infusion of NT-4/5 or BDNF. Science 1995;267:1662-1666.

50. Horch HW, Krüttgen A, Portbury SD, Katz LC. Destabilization of cortical dendrites and spines by BDNF. Neuron 1999;23:353-364.

51. Nagappan G, Zaitsev E, Senatorov VV Jr, Yang J, Hemp- 
stead BL, Lu B. Control of extracellular cleavage of ProBDNF by high frequency neuronal activity. Proc Natl Acad Sci U S A 2009;106:1267-1272.

52. Lee R, Kermani P, Teng KK, Hempstead BL. Regulation of cell survival by secreted proneurotrophins. Science 2001; 294:1945-1948.

53. Hwang JJ, Park MH, Choi SY, Koh JY. Activation of the Trk signaling pathway by extracellular zinc. Role of metalloproteinases. J Biol Chem 2005;280:11995-12001.

54. Koyama R, Yamada MK, Fujisawa S, Katoh-Semba R, Matsuki N, Ikegaya Y. Brain-derived neurotrophic factor induces hyperexcitable reentrant circuits in the dentate gyrus. J Neurosci 2004;24:7215-7224.

55. Bilousova TV, Rusakov DA, Ethell DW, Ethell IM. Matrix metalloproteinase-7 disrupts dendritic spines in hippocampal neurons through NMDA receptor activation. J Neurochem 2006;97:44-56.

56. Gu Z, Cui J, Brown S, Fridman R, Mobashery S, Strongin $\mathrm{AY}$, et al. A highly specific inhibitor of matrix metalloproteinase-9 rescues laminin from proteolysis and neurons from apoptosis in transient focal cerebral ischemia. $J$ Neurosci 2005;25:6401-6408.

57. Michaluk P, Kolodziej L, Mioduszewska B, Wilczynski GM, Dzwonek J, Jaworski J, et al. Beta-dystroglycan as a target for $M M P-9$, in response to enhanced neuronal activity. $J$ Biol Chem 2007;282:16036-16041.

58. Hübschmann MV, Skladchikova G, Bock E, Berezin V. Neural cell adhesion molecule function is regulated by metalloproteinase-mediated ectodomain release. J Neurosci Res 2005;80:826-837.

59. Oray S, Majewska A, Sur M. Dendritic spine dynamics are regulated by monocular deprivation and extracellular matrix degradation. Neuron 2004;44:1021-1030.

60. Wu YP, Siao CJ, Lu W, Sung TC, Frohman MA, Milev P, et al. The tissue plasminogen activator (tPA)/plasmin extracellular proteolytic system regulates seizure-induced hippocampal mossy fiber outgrowth through a proteoglycan substrate. J Cell Biol 2000;148:1295-1304.

61. Dziembowska M, Milek J, Janusz A, Rejmak E, Romanowska E, Gorkiewicz T, et al. Activity-dependent local translation of matrix metalloproteinase-9. J Neurosci 2012; 32:14538-14547.

62. Bouchard V, Demers MJ, Thibodeau S, Laquerre V, Fujita $\mathrm{N}$, Tsuruo T, et al. Fak/Src signaling in human intestinal epithelial cell survival and anoikis: differentiation statespecific uncoupling with the PI3-K/Akt-1 and MEK/Erk pathways. J Cell Physiol 2007;212:717-728.

63. Pankov R, Cukierman E, Clark K, Matsumoto K, Hahn C, Poulin B, et al. Specific betal integrin site selectively regulates Akt/protein kinase B signaling via local activation of protein phosphatase 2A. J Biol Chem 2003;278:1867118681.

64. Lee SR, Lo EH. Induction of caspase-mediated cell death by matrix metalloproteinases in cerebral endothelial cells after hypoxia-reoxygenation. J Cereb Blood Flow Metab 2004;24:720-727.

65. Levkau B, Kenagy RD, Karsan A, Weitkamp B, Clowes AW, Ross R, et al. Activation of metalloproteinases and their association with integrins: an auxiliary apoptotic pathway in human endothelial cells. Cell Death Differ 2002;9: 1360-1367. 